\title{
MEDICINA Y SEXUALIDAD INFANTIL EN \\ LA ESPAÑA DE LOS AÑOS TREINTA. \\ LA APORTACIÓN DEL PSICOANÁLISIS \\ A LA PEDAGOGÍA SEXUAL ${ }^{1}$
}

por

MERCEDES DEL CURA

Universidad de Castilla-La Mancha/CRIB

RAFAel HUERTAS

Instituto de Historia, C.S.I.C., Madrid

RESUMEN: El presente trabajo pretende averiguar el papel que algunos médicos desempeñaron en el desarrollo de la educación sexual de los niños en la España de los años treinta del siglo XX, prestando especial atención a los acercamientos de inspiración psicoanalítica, por entender que son éstos los más olvidados por la bistoriografía, tanto médica como general. A través del análisis de las aportaciones de los médicos españoles de la época, que tuvieron más interés por el psicoanálisis (Juarros, Sanchís Banús, Lafora y, sobre todo, Ángel Garma), se estudia la repercusión que los discursos médicos y médico-pedagógicos tuvieron en el marco del Movimiento de Reforma Sexual y, de manera más específica, en el impulso de un cambio de actitud hacia la sexualidad infantil, en sí misma, y en el desarrollo de nuevas propuestas acerca de cómo informar o "aclarar», a los niños, los misterios de la sexualidad.

Palabras clave: Medicina. Psicoanálisis. Educación sexual. España, siglo XX.

ABSTRACT: The present paper aims to discuss the role that some doctors played in the development of children's «sexual education» in 1930s Spain. Special attention is paid to approaches of a psychoanalytical inspiration that bave been overlooked by medical and general historiography, in the autbors' opinion. In order to carry out this aim, the authors study the contributions of Spanish doctors interested in psychoanalysis at the time (Juarros, Sanchis Banús, Lafora and, particularly, Angel Garma).

1 Trabajo realizado en el marco del Proyecto de Investigación BH2002-00588, subvencionado por la Dirección General de Investigación (Ministerio de Ciencia y Tecnología). 
Throughout the article, the authors analyze the influence that medical and medical-pedagogical discourses of those doctors bad on the Sexual Reform Movement. Furthermore, they point out how these discourses encouraged a change of attitude towards children's sexuality, and bow they suggested new ways of "clarifying» or telling children about the «mysteries» of sexuality.

KeY WORDS: Medicine. Psychoanalysis. Sexual education. Spain, twentieth century.

Si todavía en el siglo XVIII pudo existir, según nos explica Michel Foucault, una cierta franqueza o permisividad, en lo que al lenguaje y a la práctica de determinadas prácticas sexuales se refiere, es evidente que tal escala de valores no permaneció vigente en el siglo XIX ${ }^{2}$. Los códigos sufrieron un importante y marcado cambio, y la sexualidad se hizo una práctica privada, intimista, reducida a la unión conyugal y limitada al ejercicio de la reproducción. La norma: el silencio, y todo lo que fuera hablar de sexo se convirtió en tabú. Cualquier actividad sexual no dirigida expresamente a la reproducción de la especie iba a ser considerada ilegítima, ilegal o, incluso, patológica ${ }^{3}$.

Como es sabido, el modelo de familia burguesa tradicional, propia de la sociedad victoriana decimonónica, basada en la monogamia, pero aderezada por el adulterio de la mujer y el heterismo del marido, tenía como objetivo fundamental reforzar la figura del hombre propietario y garantizar la legitimidad del heredero, como lo escribía en 1877 el antropólogo norteamericano L. H. Morgan - cuyas investigaciones sirvieron de punto de partida a la famosa obra de Engels El origen de la familia, de la propiedad privada y del Estado ${ }^{4}$ :

«En realidad fue el desarrollo de la propiedad y el deseo de que fuera trasmitida a los hijos lo que hizo de fuerza motriz para introducir la monogamia como medio de asegurar herederos legítimos y limitar su número a la progenie efectiva de la pareja conyugal» 5 .

Obviamente, la hipocresía burguesa — la famosa «doble moral»- recurrió a vías de escape, a nuevos espacios ocultos que permitieron mantener el silencio y las buenas formas en sociedad, relegando las «sexualidades ilegítimas» a luga-

2 Foucault, Michel: Histoire de la sexualité. 1. La volonté de savoir, Paris, Gallimard, 1976.

3 BALBO, Eduardo y HUERTAS, Rafael: «La sexualidad y sus límites», Asclepio (Madrid), vol. 42 (1990), $\mathrm{n}^{\circ}$ 2, pp. 3-8. Ver también HUERTAS, Rafael: «El concepto de «perversión» sexual en la medicina positivista», Ibid., pp. 89-109.

4 ENGELS, Friedrich: El origen de la familia, de la propiedad privada y del Estado, Madrid, Ayuso, 1975 [ed. original, 1884].

5 MORGAN, Lewis Henry: Ancient Society, or Researches in the Lines of Human Progress from Savagery through Barbarism to Civilization, London, MacMillan and Co, 1877. La cita textual está tomada de la versión castellana titulada La Sociedad Primitiva, Madrid, Ayuso, 1971, p. 475.

Hispania, LXIV/3, núm. 218 (2004) 987-1002 
res específicos donde poder reinscribirlas, si no en los circuitos de producción, al menos en los de ganancia:

«El burdel o el manicomio serán esos lugares de tolerancia: la prostituta, el cliente y el rufián, el psiquiatra y su histérico»6.

En definitiva, todo aquello que no apuntara a la reproducción - de los individuos o del sistema - se situó fuera de la norma social, de la ley y de la moral, se trasladó a una realidad paralela, se olvidó, se silenció, dejó de existir. Eso ocurrió, durante años, con la sexualidad infantil: los niños carecían de sexo, razón suficiente para prohibírselo, para ignorarlo, para no hablar de él. Una vez más, Foucault nos recuerda que:

«Tal sería lo propio de la represión y lo que la distingue de las prohibiciones que mantiene la simple ley penal: funciona como una condena de desaparición, pero también como orden de silencio, afirmación de la inexistencia y, por consiguiente, comprobación de que de todo eso nada hay que decir, ni ver, ni saber» 7 .

Sin embargo, la segunda mitad del siglo XIX fue un momento en el que, como bien ha indicado T. Tanner, «se resquebrajan los sistemas tradicionales, se desacreditan los valores burgueses y se empieza a dudar de la santidad del matrimonio y de la impermeabilidad de las clases sociales» ${ }^{8}$. Esta decadencia fin de siglo de los valores establecidos favoreció, entre otras cosas, un incipiente movimiento de liberación de la mujer. Comenzaba a aparecer una «mujer incomprendida» que, en contraposición al modelo de "esposa y madre», sería tildada de neurótica, histérica, cuando no de lesbiana o «marimacho»9. Ante los nuevos imperativos sociales, la reorganización del discurso y de los mecanismos disciplinarios resultó obligada.

Fue, precisamente, en el último cuarto del siglo XIX cuando surgió con fuerza el discurso de la «educación sexual». La represión y el silencio fueron dejando paso, poco a poco, a un control más sutil que puso en marcha métodos reguladores y estrategias de "prevención». No sin debate acerca de su conveniencia, la sexualidad infantil se convertiría en objeto de la pedagogía, y su abordaje permitiría tanto el encauzamiento individual del futuro ciudadano, como la interiorización colectiva de los riesgos que conllevaba la sexualidad ${ }^{10}$.

6 FOUCAULT, Michel: Historia de la sexualidad, versión castellana, Madrid, Siglo XXI, 1987, p. 10

7 lbid.

8 TANnER, Tony: Adultery in the novel: Contract and transgresion, Baltimore, John Hopkins University Press, 1979 , p. 9.

9 Para España, ver SimON PALMER, María del Carmen: «Las neurosis femeninas y la educación española», Asclepio (Madrid), vol. 35 (1983), pp. 327-342.

10 Ver VázQuez García, Francisco y Moreno Mengibar, Andrés: Sexo y Razón. Una genealogía de la moral sexual en España (siglos XVI-XX), Madrid, Akal, 1997, pp. 131 y ss. 
Nuestro objetivo, en las líneas que siguen, es analizar el papel que algunos médicos desempeñaron en el desarrollo de la educación sexual de los niños en la España de los años treinta del siglo XX, época de máximo apogeo del discurso sexopedagógico, prestando especial atención a los acercamientos de inspiración psicoanalítica, por entender que son éstos los más olvidados por la historiografía, tanto médica como general.

\section{EDUCACIÓN, MEDICINA Y REFORMA SEXUAL}

Aunque existe en España una cierta literatura sexológica publicada en el siglo XIX ${ }^{11}$, es a comienzos del XX cuando se detecta un aumento de la misma y un especial interés por los aspectos pedagógicos. Francisco Vázquez García y Andrés Moreno Mengibar han establecido tres etapas en el desarrollo de la sexopedagogía del primer tercio del siglo XX en España que nos parecen acertados.

En un primer momento (entre 1900 y 1919), tiene lugar no sólo la traducción de obras extranjeras importantes, como las de Havelock Ellis (1859-1939) entre 1906 y 1913 o en 1911 las de August Henri Forel (1848-1931) - cuya obra Questions sexuelles exposées aux adultes cultivés, publicada en 1905, llegó a ser traducida a quince idiomas-, sino también la aparición de las primeras monografías y ensayos de educación sexual, entre los que destacan, ya en la segunda década del siglo XX, los tratados de Antonio Piga y Pascual ${ }^{12}$, y de César Juarros (1879-1942) ${ }^{13}$, ambos vinculados al Instituto de Medicina Social ${ }^{14}$.

En una segunda etapa, correspondiente a los años veinte, surgen las iniciativas de los reformadores sexuales, en las que prima un discurso de "cruzada» $y$ adoctrinamiento de la población que, vinculado al movimiento feminista, persigue una "reforma sexual» a través de diversos medios, como la prensa diaria - las páginas de El Sol fundamentalmente-, conferencias en Ateneos y foros diversos, y la creación de organizaciones, como la Sociedad de Abolicionismo de la prostitución, presidida por Juarros desde 1922, que pretendía, además de una reforma de la reglamentación de la prostitución, una amplia campaña de higiene y educación sexual.

Citemos también la Liga de Educación Social, de orientación netamente feminista, fundada en 1928, o la Sociedad de Amigos del Niño, que promovería la celebración del Primer Curso Eugénico Español, evento que finalmente sería suspendido por el gobierno, hecho que, lejos de frenar el impulso de sus organizadores, no hizo sino difundir y reforzar la imagen de militancia progre-

\footnotetext{
11 SÁNCHeZ Granjel, Luis: «El sexo como problema en la España contemporánea (pesquisa bibliográfica)", Cuadernos de Historia de la Medicina (Salamanca), $n^{\circ} 13$ (1974), pp. 111-131.

12 Piga y Pascual, Antonio: Higiene de la Pubertad, Toledo, Vda e Hijos de J. Peláez, 1910.

13 JuARros, César: Normas de Educación Sexual y Física, Madrid, Renacimiento, s.f.

14 Álvarez Peláez, Raquel: «El Instituto de Medicina Social. Primeros intentos de institucionalizar la eugenesia», Asclepio (Madrid), vol. 40 (1988), n 1, pp. 343-358.
} 
sista de estos reformadores sexuales, frente al conservadurismo - sexual y político- de la dictadura de Primo de Rivera ${ }^{15}$.

Finalmente, los años de la $\mathrm{II}^{\mathrm{a}}$ República (en particular los del primer bienio), se caracterizan, como en tantos órdenes de la vida española ${ }^{16}$, por un avance de las posiciones de progreso y por el intento de llevar a cabo, en la práctica, las reformas legislativas pertinentes. En 1932, se crea la Liga Española para la Reforma Sexual sobre Bases Científicas, filial de la Weltliga für Sexual Reform, que había sido fundada en 1928. Dicha organización, impulsada por la famosa Hildegart y por su madre, Aurora Rodríguez, estuvo apoyada, desde sus inicios, por personalidades de la ciencia y de la cultura española y se constituyó en secciones, una de las cuales fue la de "Pedagogía Sexual», dirigida por el pedagogo y eugenista Luis Huerta, quien contó con la colaboración de Francisco Blanco y J. Burgallo ${ }^{17}$. La Liga tuvo como órgano de expresión la revista Sexus y fue capaz de organizar las Primeras Jornadas Eugénicas Españolas, retomando el talante de aquel Primer Curso Eugénico que, años antes, no había llegado a celebrarse ${ }^{18}$.

Es en este marco, en el que la sexualidad infantil adquiere, finalmente, un protagonismo que obliga a pedagogos, médicos, psiquiatras y psicoanalistas a reflexionar sobre las posibilidades que, como profesionales, pueden y deben desarrollar en este ámbito. César Juarros, en una conferencia sobre «Igualdad sexual" pronunciada en 1927, se lamenta así de la «despreocupación por educar al niño en sus primeros años, dejándolo para cuando su psicología está endurecida», y llega a afirmar categóricamente: «El niño tiene sexualidad» ${ }^{19}$. La conferencia aludida fue pronunciada por Juarros en la sede de la Federación Tabaquera (Centro de Cigarreras y Tabaqueras), el más importante sindicato femenino de la época y uno de los ejes de las actividades feministas ${ }^{20}$.

15 VÁzquez García, Francisco y Moreno Mengibar, Andrés: Sexo y Razón, op. cit., p. 134. Los avatares que dieron lugar a la suspensión gubernativa del evento quedan explicados en PÉrEz SANZ, Pilar y BrU, Carmen: «La sexología en la España de los Años Treinta», Revista de Sexología (Madrid), $\mathrm{n}^{\circ} 30$ (1987), pp. 13 y ss.

16 Para el ámbito sanitario, la bibliografía es abundante. Ver, entre otros: MAZUECOS, Antonio: «La política social socialista durante el primer bienio republicano: trabajo, previsión y sanidad», Estudios de Historia Social (Madrid), nº 14 (1982), pp. 135-146; HuERTAS, Rafael: «Política sanitaria: de la Dictadura de Primo de Rivera a la II ${ }^{\mathrm{a}}$ República», Revista Española de Salud Pública (Madrid), $\mathrm{n}^{\circ} 74(2000)$, pp. 37-45

17 Ver Álvarez Peláez, Raquel y HUERTAS, Rafael: ¿Criminales o locos? Dos peritajes psiquiátricos del Dr. Gonzalo R. Lafora, Madrid, C.S.I.C., 1987, pp. 89 y ss.

18 NOGERA, Enrique: «Como se yuguló la generosa idea del Primer Curso Eugénico Español», en Nogera, Enrique y Huerta, Luis (eds.): Genética, eugenesia y pedagogía sexual. Primeras Jornadas Eugénicas Españolas, Madrid, Javier Morata, 1934, t. II, pp. 405-406. Ver ÁlvAREZ PeláEZ, Raquel: «Origen y desarrollo de la eugenesia en España», en SÁNCHEZ RON, José Manuel (ed.): Ciencia y Sociedad en España. De la Ilustración a la Guerra Civil, Madrid, El Arquero-C.S.I.C., 1988, pp. 178-204.

19 El Sol (Madrid), 27 de noviembre de 1927.

20 Ver GLICK, Thomas F.: «Psicoanálisis, reforma sexual y política en la España de entreguerras», Estudios de Historia Social (Madrid), n 16-17 (1981), pp. 7-25. 
El niño tiene sexualidad, la niña también: feliz descubrimiento pero, al mismo tiempo, grave problema, pues son demasiados años de silencio, de represión y ocultación. Es preciso, pues, ponerse al día; y la medicina, uno de los grandes saberes normativos, que había prestado gustosa su discurso para patologizar las supuestas desviaciones sexuales ${ }^{21}$, debe ahora apropiarse de, al menos, una parte de la sexología como saber emergente y, de manera particular, de la pedagogía sexual. El médico sigue queriendo desempeñar un papel de "experto" en las cuestiones del cuerpo (y de la mente) e insiste, al igual que los nuevos pedagogos, en que la educación sexual debe hacerse «sobre bases científicas». No debe extrañarnos, en este sentido, el repentino interés de determinados colectivos de especialistas médicos por los temas de educación sexual, recogiendo así tanto las inquietudes de la opinión pública como posibles necesidades de legitimación científica y social.

En 1930, la Sociedad Española de Higiene premia dos monografías sobre la misma problemática: la de J. Bugallo Sánchez, La Higiene sexual en las escuelas, y la de L. Huerta, La educación sexual del niño y del adolescente; recuérdese que ambos autores premiados colaborarán, dos años más tarde, en la sección de «Pedagogía Sexual» de la Liga Española para la Reforma Sexual sobre Bases Científicas. Asimismo, la Liga Española de Higiene Mental propone en 1930, entre los temas a tratar en el Congreso de 1932, el de la Educación Sexual, «por ser esta una cuestión de gran importancia y que interesa a médicos, pedagogos, filósofos, juristas y psiquiatras»22.

«iHablemos de sexo!», esa parece ser la consigna generalizada entre el amplio colectivo de profesionales que piensa que la reforma sexual ha de formar parte ineludible de la regeneración social. iHablemos de sexo!, pero hablemos con propiedad, aclarando científicamente las ideas erróneas, las interpretaciones "peligrosas» y, en definitiva, los mitos y creencias injustificados. Y así, la «Sexuelle Aufklärung» de los alemanes irrumpe en la literatura médica española: la «revelación de lo sexual» o la «ilustración aclaratoria de lo sexual» se arrogará la misión de criticar y proscribir las explicaciones mundanas y «arrabaleras» de la sexualidad y sustituirlas por informaciones bien medidas que favorezcan en el niño una sexualidad «honesta» y sin riesgos para la salud, ni para la moral. En palabras de Lafora:

21 LANTÉRI-Laura, Georges: Lecture des Perversions. Histoire de leur appropiation médicale, Paris, Masson, 1979.

22 RODRÍGUEZ LAFORA, Gonzalo y COMAS, Margarita: La educación sexual y la coeducación de los sexos, Buenos Aires, Losada, 1947, p. 9. Este libro, publicado en la República Argentina en los años cuarenta, recoge dos textos, uno de Lafora («La educación sexual») y. otro de Margarita Comas («La coeducación de los sexos»), que habían aparecido con anterioridad en la Revista de Pedagogía. La cita está tomada del «Prefacio» que. Lafora hace de su texto para esta última edición. En lo sucesivo, se citará por el original de 1932.

Hispania, LXIV/3, núm. 218 (2004) 987-1002 
«Vale más una ilustración sexual bien dirigida por persona ilustrada que no la ilustración libre adquirida en la calle («wilde Aufklärung» o aclaración libre de los alemanes)»23.

Aunque el objeto último de la educación sexual es el niño o el adolescente, el discurso pedagógico va dirigido también, y fundamentalmente, a los padres y a los maestros. Ya que, según afirma César Juarros en una conferencia pronunciada en el Ateneo de Divulgación Social en 1929 y titulada «El placer ajeno»:

«La sexualidad infantil [está] lamentablemente desatendida por la mayoría o la totalidad de los padres, que no conciben al niño apetencias sexuales, siendo así que las más arraigadas aberraciones de los sexos tiene su incitación en la misma cuna» 24 .

Existe, pues, una finalidad preventiva de primer orden, no sólo de profilaxis antivenérea, o de los vicios y las desviaciones sexuales, sino también de regulación de los comportamientos sociales. Esta apuesta por «aclarar» los misterios de la sexualidad no resulta uniforme; dirigido preferentemente a la burguesía, el discurso se va transformando cuando éste se pretende orientar hacia las clases populares, con la intención de combatir la revelación descuidada o la iniciación brutal - producto, en realidad, de la menor separación entre adultos y niños en ese medio social-. En general, se pretende reforzar los lazos afectivos en el hogar y que el padre, tanto como la madre, asuma sus responsabilidades privadas y abandone sus formas tradicionales de sociabilidad, volcadas al exterior del hogar ${ }^{25}$. Higiene y moral vuelven a darse la mano con sutileza pero con eficacia ${ }^{26}$.

Sin embargo, en este marco general de la educación sexual, y de las técnicas de la «aclaración» de lo sexual desarrolladas en los años treinta en España, aparece un enfoque que no ha sido suficientemente reconocido por los historiadores de la educación, ni de la sexualidad. Nos referimos al psicoanálisis y a sus posibilidades en el contexto de la pedagogía sexual. Es cierto que las fuentes son escasas y que el discurso psicoanalítico no tendrá un peso y una influencia

23 ROdríguez Lafora, Gonzalo: «La educación sexual», Revista de Pedagogía (Madrid), n 11 (1932), p. 486

24 El Sol (Madrid), 19 de febrero de 1929. Ver Glick, Thomas F.: «Psicoanálisis, reforma sexual y política en la España de entre-guerras», op. cit., p. 18.

${ }_{25}$ Los cambios de discurso educativo, dependiendo de la clase social que se considere, pueden verse en la mayoría de los publicistas de la época y han sido muy bien vistos por VÁzQUEZ GARCíA, Francisco y MORENO Mengibar, Andrés: Sexo y Razón, op. cit., p. 138.

26 Ver CAMPOS, Ricardo: «La sociedad enferma: Higiene y moral en España en la segunda mitad del siglo XIX y principios del XX», Hispania (Madrid), vol. 55, (1995), pp. 1093-1112. Sobre el hogar como espacio de moralización y prevención, ver CAMPOS, Ricardo: «Casas para obreros. Un aspecto de la lucha antialcohólica en España durante la Restauración», Dynamis (Granada), $n^{\circ} 14$ (1994), pp. 111-130. 
mayoritaria en la España de los veinte y los treinta, pero no por eso deja de ser interesante valorar su papel y sus aportaciones en un intento de completar nuestra idea sobre la problemática historiográfica que estamos considerando.

\section{PSICOANÁLISIS Y PEDAGOGÍA}

La recepción del psicoanálisis en España a lo largo de las primeras décadas del siglo XX ha sido suficientemente estudiada de manera general por diversos autores $^{27}$. Entre los médicos más comprometidos con la reforma sexual, José Sanchís Banús (1893-1932) y César Juarros fueron los que más argumentos psicoanalíticos utilizaron. Recuérdese que el Proyecto de Ley sobre el divorcio, presentado ante las Cortes en 1931 y elaborado por el jurista Luis Jiménez de Asúa (1889-1970), fue defendido por el psiquiatra y diputado socialista Sanchís Banús utilizando argumentos psicoanalíticos: el divorcio vendría a ser una forma de prevención de la histeria, al proporcionar a la mujer un medio legal de protegerse, evitando así una reacción histérica por «falta de defensa» 28 .

Por su parte, César Juarros insistiría repetidamente en la importancia del psicoanálisis en la comprensión de la sexualidad infantil y su necesaria utilización en cualquier programa de educación sexual ${ }^{29}$, idea que fue recogida en un informe - al parecer, elaborado por Emilio Mira (1890-1964) - presentado por la Liga Española de Higiene Mental al Ministerio de Gobernación en 1933, en el que se afirmaba que «según algunos psicoanalistas, debe incluso tratarse con el niño y el adolescente de todo lo referente a las tendencias incestuosas de ese periodo evolutivo sexual» ${ }^{30}$.

También en el mundo de la pedagogía, empezaban a discutirse el psicoanálisis y sus posibles aplicaciones a la educación infantil. La propia Institución Libre de Enseñanza recogía, en las páginas de su Boletín, algunas reflexiones al respecto. Se apuntaba así que «toda educación bien conducida debe considerar la sexualidad»:

«La educación psicoanalítica tiene por objeto esencial la misión de triunfar sobre las imágenes sexuales presentes, pero rechazadas, que paralizan el desarrollo

\footnotetext{
27 GLICK, Thomas F.: «Psicoanálisis, reforma sexual y política en la España de entre-guerras», op. cit., y «El impacto del psicoanálisis en la psiquiatría española de entreguerras», en SÁNCHEZ RoN, José Manuel (ed.): Ciencia y Sociedad en España, op. cit., pp. 205-221; LÁZARO, José S.: «La recepción de Freud en la cultura española (1893-1983)", Medicina e Historia (Barcelona), n 41 (1991), pp. 5-28; Carles, Francisco, MuÑoz, Isabel, Llor, Carmen, Marset, Pedro: Psicoanálisis en España (1893-1968), Madrid, A.E.N., 2000.

28 La intervención de Sanchís Banús está recogida en el Diario de Sesiones de las Cortes Constituyentes de la II República (Madrid), $\mathrm{n}^{\circ}$ 57, 15 de octubre de 1931, pp. 1759-1764.

29 JUARROS, César: Los horizontes del psicoanálisis, Madrid, Mundo Latino, 1929, p. 118.

30 Ver GLICK, Thomas F.: «Psicoanálisis, reforma sexual y política en la España de entreguerras", op. cit., p. 18.
}

Hispania, LXIV/3, núm. 218 (2004) 987-1002 
moral del niño. No se obtiene este resultado exhortando a los niños a no pensar cosas obscenas; tal temperamento tendría consecuencias enojosas, porque provocaría nuevos rechazos en el dominio de la actividad inconsciente»31.

Sin embargo, al igual que muchos médicos se mostraban hostiles al psicoanálisis, los recelos y cautelas de los pedagogos eran también muy evidentes:

«El psicoanálisis es un arma de dos filos que debe manejarse con mucha prudencia. [...] Es preferible prescindir del psicoanálisis en los niños antes que lanzarse a una investigación desenfrenada» 32 .

En definitiva, se reconocían «los influjos perniciosos que pueden ejercer sobre el alma infantil, según muestra el psicoanálisis, el silencio mantenido por los padres acerca de la cuestión sexual» ${ }^{33}$, pero se discutía que en el alma infantil hubiese un predominio absorbente y radical del instinto sexual, indicando que la pedagogía no era una psiquiatría aplicada y que cada profesional tenía su espacio de actuación y su jurisdicción científica.

Sin embargo, fue otra publicación pedagógica, vinculada también al institucionismo, la que ofreció a los médicos y psiquiatras un espacio privilegiado de colaboración e intercambio. La Revista de Pedagogía, fundada en 1922 por Lorenzo Luzuriaga (1889-1959) - pedagogo perteneciente al grupo de Ortega e inspirador de diversos programas educativos socialistas-, publicó artículos de Gonzalo Rodríguez Lafora (1886-1971) ${ }^{34}$, o de Emilio Mira ${ }^{35}$, sobre diversos aspectos psicopedagógicos, así como dos trabajos estrictamente psicoanalíticos de Ángel Garma (1904-1993), quien obtiene en 1933 una plaza de psiquiatra en el Tribunal Tutelar de Menores, donde tiene oportunidad de colaborar con el ju-

31 Beltrán, J. Ramón: «El psicoanálisis en sus relaciones con la pedagogía», Boletín de la Institución Libre de Enseñanza (Madrid), n 787 (1925), p. 298.

32 Ibid., p. 300.

33 BARNÉS, Domingo: «El psicoanálisis y la educación», en Boletín de la Institución Libre de Enseñanza (Madrid), $\mathrm{n}^{\circ} 781$ (1925), p. 109.

34 RODRígueZ LAFORA, Gonzalo: «Los estados psicopáticos en la escuela. Los impulsivos», Revista de Pedagogía (Madrid), $\mathrm{n}^{\circ} 1$ (1922), pp. 81-85; "Delincuencia infantil y deficiencia mental», Ibid., n ${ }^{\circ} 5$ (1926), pp. 551-555; «Sobre la educación de los deficientes mentales», Ibid., no 6 (1927), pp. 113-121; «Métodos psicotécnicos aconsejables para el estudio de la personalidad», Ibid., $\mathrm{n}^{\circ} 11$ (1932), pp. 97-108; «La educación sexual», Ibid., n 11 (1932), pp. 481-490 y 543-549; «La jornada escolar del niño y del maestro», Ibid., no 12 (1933), pp. 145-153.

35 MirA, Emilio: «¿Qué es la inteligencia?», Revista de Pedagogía (Madrid), n 1 (1922), pp. 5662; «El estado actual de las pruebas mentales», Ibid., n 2 (1923), pp. 241-247 y 298-306; "Las pruebas de imaginación visual en la escuela», Ibid., n 3 (1924), pp. 281-284; "El aspecto pedagógico de la orientación profesional», Ibid., $\mathrm{n}^{\circ} 4$ (1925), pp. 145-152; «La exploración de la afectividad en la escuela», Ibid., n ${ }^{\circ}$ (1926), pp. 481-486; "Pruebas de afectividad en la escuela», Ibid., $\mathrm{n}^{\circ}$ 6 (1927), pp. 183-190; «El desarrollo de las funciones mentales en el niño», Ibid, , $\mathrm{n}^{\circ} 7$ (1928), pp. 529-535; "Cómo se exploran las aptitudes psíquicas», Ibid., nº 9 (1930), pp. 97-105 y 171-176; «Pruebas para el reconocimiento de la inteligencia abstracta», Ibid., $\mathrm{n}^{\circ} 10$ (1931), pp. 49-56. 
rista Luis Jiménez de Asúa, director entonces del Consejo de Protección a la Infancia, y con la pedagoga María Luisa Navarro, esposa de Lorenzo Luzuriaga ${ }^{36}$.

Este interés de los psiquiatras por la educación infantil y por interactuar con maestros y pedagogos tuvo que ver, obviamente, con las conexiones entre médicos y educadores en el marco de los proyectos de reforma social. José Ortega y Gasset (1883-1955) fue, no cabe duda, uno de los nexos entre unos y otros, pues no en vano figuraba, junto a Lafora y Sacristán, como el «tercer» director de los Archivos de Neurobiología ${ }^{37}$. Tampoco debió ser ajeno Ortega a una mayor apertura y sensibilidad hacia el psicoanálisis por parte de los pedagogos. No en vano había sido el autor del Prólogo a la primera edición de las Obras Completas de Sigmund Freud en castellano (la edición de Biblioteca Nueva de 1922) ${ }^{38}$.

Ángel Garma, considerado «el primer psicoanalista español» ${ }^{39}$, había llegado a España en 1931, tras completar su formación psicoanalítica en Alemania. Inmediatamente, inició una labor de divulgación y de difusión del psicoanálisis entre sus colegas y otros profesionales, publicando artículos diversos sobre teoría y clínica, algunos de los cuales abordaron aspectos relativos a la sexuali$\mathrm{dad}^{40}$. Pero es en el trabajo titulado «Psicología de la aclaración de la sexualidad en la infancia», publicado en 1934 en la Revista de Escuelas Normales ${ }^{41}$, donde con más claridad —y autoridad científica — pueden objetivarse las relaciones entre psicoanálisis y pedagogía en la España de preguerra. La «Sexuelle Aufkläurung» cobra aquí una dimensión diferente: su objetivo no es ni la reforma de la moral sexual, ni el abordaje científico y veraz de la información sexual, sino la prevención de determinados trastornos psíquicos, como la neu-

36 GARMA, Ángel: «La higiene mental en la infancia. Consideraciones psicoanalíticas», Revista de Pedagogía (Madrid), $\mathrm{n}^{\circ} 11$ (1932), pp. 13-25; «Los sueños de angustia en la infancia», Ibid., $\mathrm{n}^{\circ} 12$ (1933), pp. 308-315.

37 Sobre el papel que el prestigio de Ortega desempeña en la legitimación del proyecto institucionalizador de la psiquiatría española de los años veinte, puede verse HUERTAS, Rafael: Organizar y persuadir. Estrategias profesionales y retóricas de legitimación de la medicina mental española (1875-1936), Madrid, Frenia, 2002, p. 110.

38 Ver Colina, Fernando: «José Ortega y Gasset, Prólogo a Obras Completas de Sigmund Freud», Clínica y Pensamiento (Madrid), nº 2 (2002), pp. 127-132.

39 GómEZ SÁNCHEZ-GARNICA, José María: La aportación de Ángel Garma al psicoanálisis actual, Tesis doctoral, Madrid, Universidad Autónoma de Madrid, 1993; CARLES, Francisco et al, Psicoanálisis en España, op. cit., pp. 139 y ss.; HuERTAS, Rafael: Los médicos de la mente. De la neurología al psicoanálisis, Madrid, Nívola, 2002, pp. 61 y ss.

40 Garma, Ángel: «Consideraciones psicoanalíticas sobre la vida sexual», Archivos de Neurobiología (Madrid), vol. 12 (1932), n 4, pp. 543-566, artículo reproducido en GARMA, Ángel: El psicoanálisis, la neurosis y la sociedad, Madrid, Ediciones de Archivos de Neurobiología, 1936, pp. 42-50. En lo sucesivo se cita por esta última edición.

41 GARMA, Ángel: «Psicología de la aclaración de la sexualidad en la infancia», Revista de Escuelas Normales (Guadalajara), vol. 12 (1934), n 103, pp. 98-103. El artículo se reprodujo, como capítulo (titulado «Psicoanálisis y pedagogía. Valor psicológico de la aclaración de la sexualidad») en GARMA, Ángel: El psicoanálisis, la neurosis y la sociedad, op. cit., pp. 115-123. En lo sucesivo se cita por esta última edición.

Hispania, LXIV/3, núm. 218 (2004) 987-1002 
rosis o las «perversiones», que pueden tener su origen en una sexualidad infantil reprimida.

\section{LA ACLARACIÓN DE LA SEXUALIDAD Y SU VALOR PSICOLÓGICO}

La «aclaración de la sexualidad» - la «Sexuelle Aufkläurung» de los pedagogos alemanes-, definida como una técnica educativa consistente en «explicar al niño qué es la sexualidad y qué papel tiene o debe tener en la vida de un individuo ${ }^{42}$, tiene, para Garma, una serie de inconvenientes que limitan su valor médico-pedagógico. La primera y fundamental crítica que Garma plantea es que la «aclaración sexual» debe ser algo más que una «explicación intelectual», siendo necesario "exponer al niño, no solamente cómo es la sexualidad del adulto, sino también cómo es la sexualidad infantil y cómo debe manejar sus tendencias sexuales infantiles", ya que "la neurosis puede ser una consecuencia no solamente de la represión de una sexualidad que presenta parecidos con la del adulto, sino también de la represión de instintos que en el adulto no existen ${ }^{43}$.

De esta circunstancia se deriva una de las dificultades de dicho modelo de educación sexual, o sea la incapacidad del adulto para explicar la sexualidad del niño, sencillamente porque no la conoce, porque ya no la recuerda:

«El adulto no puede aclarar la sexualidad del niño, porque para él la sexualidad infantil es algo así como un lenguaje que una vez poseyó, pero que desde entonces se ha olvidado y del cual se recuerdan solamente algunas palabras»44.

Además, esta aclaración de la sexualidad, por afortunada que pueda llegar a ser, no libra al niño de los factores ambientales y constitucionales que, según Garma, intervienen en la génesis de las neurosis. La educación sexual no permite modificar la constitución desfavorable que se halla en la base de todas las neurosis; tan sólo puede intervenir, y siempre de modo parcial, en las vivencias que obran sobre ella. Existen, por tanto, acontecimientos del mundo exterior incontrolables que pueden afectar la líbido del niño (prurito en la zona genital, pérdida del padre, parásitos en el ano) y generar neurosis ${ }^{45}$.

En definitiva, para Garma, "la aclaración de la sexualidad tiene un valor bastante pequeño» ${ }^{46}$, cuando no resulta directamente perjudicial para la salud mental del niño, dado el riesgo de que las explicaciones sean imperfectas o inadecuadas: por ejemplo, cuando se pretende enseñar al niño, en cuanto éste llega a una edad determinada, todo lo que anteriormente se había mantenido en secre-

\footnotetext{
42 GARMA, Ángel: El psicoanálisis, la neurosis y la sociedad, op. cit., p. 115.

43 Ibid., pp. 118-119.

44 Ibid., p. 119.

45 Ibid.

46 Ibid., p. 121.
} 
to. Este error pedagógico es denunciado por nuestro psicoanalista, indicando que es consecuencia de «la mezcla de $[\ldots .$.$] dos tendencias, una que procura ne-$ gar la sexualidad infantil y otra que intenta colocarla en su justo lugar». Lo correcto, en todo caso, es aclarar al niño sus problemas sexuales desde el primer momento en que demuestra su interés por ellos:

"Como el interés del niño va paso a paso y de un terreno a otro, la explicación debe seguir constantemente el mismo camino del interés y debe ir a la misma velocidad $\gg 47$.

La falta de interés por la sexualidad denota pues debilidad mental, no haber alcanzado la fase genital de desarrollo o tener miedo a formular esas preguntas. Es necesario, además, valorar la edad en que la que se realiza la ilustración, no sólo porque cada individuo reacciona según su edad sino porque el valor de esta aclaración será muy distinto. Para Garma, la aclaración hecha en la pubertad o en época posterior apenas tiene valor e, incluso, puede ser contraproducente, sobre todo si, hasta ese momento, la educación ha estado ligada a la represión sexual. El adolescente educado para rechazar o negar la sexualidad, podría desarrollar una resistencia frente a esta ilustración tardía, lo que le llevaría a avivar sus represiones y a desconfiar de las personas de su alrededor.

¿Qué posición asumir, entonces, respecto a la sexualidad del niño?, ¿Qué valor tiene el papel desempeñado por los padres, maestros, etc., en este proceso de aclaración de la sexualidad? La actitud defendida por Garma es dejar que el niño se enfrente con los problemas y procure resolverlos por sí mismo, contestarle siempre con la verdad cuando pida ayuda; $y$, desde el momento en que nace, no reprimir sus tendencias sexuales, para evitar que se desarrolle una reacción de asco hacia la sexualidad. La labor del adulto se limita, por tanto, a «ayudarle en su investigación e impedir el que cree represiones» ${ }^{48}$.

Veracidad y tolerancia, en definitiva, serán los dos elementos fundamentales que el adulto responsable deberá tener en cuenta al abordar la sexualidad infantil desde un punto de vista médico-pedagógico. Los ejemplos que Garma utiliza para ilustrar esta recomendación son suficientemente expresivos. En relación a la veracidad, «el niño al que se le obliga a creer que los niños vienen de París, se le estropea en parte la lógica del pensamiento ${ }^{49}$. Otros autores se muestran más cautos. Lafora, por ejemplo, está convencido de que «este sentimiento de lo natural como primera fase de la ilustración sexual tiene sus límites, pues una excesiva verdad puede perjudicar al niño» ${ }^{50}$.

En cuanto a la tolerancia, la actitud del adulto - padres o educadoresante la masturbación es, obviamente, una de las mejores reflexiones a las que se

47 Ibid., pp. 117-118.

48 Ibid., p. 122

49 Ibid., p. 118

50 ROdRíGUeZ Lafora, Gonzalo: «La educación sexual», op. cit., p. 484.

Hispania, LXIV/3, núm. 218 (2004) 987-1002 
puede recurrir. Para Garma, «el niño satisface sus deseos genitales por medio de la masturbación» ${ }^{51}$. Tal afirmación, planteada así, con toda naturalidad, rompe con las creencias, arrastradas desde siglos, de que el onanismo es perjudicial para la salud física, mental y moral del individuo ${ }^{52}$. Es más, la masturbación es vista como la posibilidad más lógica que tiene el niño (y la niña) para «descargar» su libido (energía sexual). El consejo de Garma es, precisamente, la tolerancia: no interferir en lo que entiende que forma parte de la evolución y desarrollo normal de la sexualidad infantil, advirtiendo que:

«Si se prohibe [al niño] la masturbación amenazándole con toda clase de castigos, el niño seguirá masturbándose secretamente; pero esta masturbación irá acompañada de sentimientos de culpabilidad y por tanto, de remordimientos y de neurosis» 53 .

Tal afirmación, hecha en 1934, aparentemente asumida ya por un número importante de psiquiatras y psicoanalistas ${ }^{54}$, no siempre iba a ser aceptada sin reservas por autores de reconocido prestigio. La actitud de Lafora, por ejemplo, ante el "problema» de la masturbación es confusa y ambivalente, pues aunque reconoce que es la «forma primaria de la descarga erótica, que debemos considerar como función normal de la mayoría de los niños», y que «la educación sexual de la pubertad debe evitar el conceder excesiva importancia a esta tendencia a la autosatisfacción erótica» ${ }^{55}$, se apresura a advertir sobre las consecuencias insanas del abuso excesivo de la masturbación, llegando a recomendar que, en los niños y adolescentes, «los bolsillos no deben ponerse en la parte lateral o anterior de los pantalones, pues facilitan la tendencia a la masturbación” ${ }^{56}$.

En definitiva, la revelación de lo sexual en Garma no tiene la carga moral reflejada en la obra de Lafora. Para este autor, «la educación sexual de la infancia no es más que un segmento o eslabón de una cadena de conocimientos ligados con problemas de conducta referentes a la vida sexual en las edades posteriores de la vida, la cual está sometida fundamentalmente a un sistema de ideas morales, a una filosofía y a una ética» ${ }^{57}$. No está orientada hacia una moral de la conducta; es decir, no busca producir un tipo de comportamiento y

s1 GARMA, Ángel: El psicoanálisis, la neurosis y la sociedad, op. cit., p. 43.

52 SEOANE, José Benito: «Onanismo y perversión: el discurso de los saberes «expertos» en la España de finales del siglo XIX y principios del siglo XX», en MARTíNEZ-PÉREZ, José, PORRAS, $\mathbf{M}^{2}$ Isabel, SAMBLÁs, Pedro y DEL CURA, Mercedes (eds.): La medicina ante el nuevo milenio: una perspectiva histórica, Cuenca, Ediciones de la Universidad de Castilla-La Mancha, 2004, pp. 879-894.

53 GARMA, Ángel: El psicoanálisis, la neurosis y la sociedad, op. cit., p. 118.

54 Sobre las posiciones de los psicoanalistas ante la masturbación, ver el capítulo titulado «El sexo de los ángeles» en Álvarez-Uría, Fernando y Varela, Julia: Las redes de la Psicología. Análisis sociológico de los códigos médico-psicológicos, Madrid, Libertarias/Prodhufi, 1994 (2ª ed.), pp. 99-149.

s5 RODRÍGUEZ LAFORA, Gonzalo: «La educación sexual», op. cit., pp. 548 y 549.

56 Ibid., p. 483.

57 Ibid., p. 481. 
conocimiento ético relativo a la vida sexual tanto en la infancia como en la edad puberal. Pero no debemos llamarnos a engaño: el psicoanálisis no renuncia, en ningún momento, a su vocación normativa. No todo ha de ser tolerancia en la actitud pedagógica sobre el sexo, según aclara Garma:

«En el niño existen deseos que deben ser tolerados y otros cuya satisfacción no debe llevarse a cabo, sino que deben ser desviados de su meta inmediata. Por ejemplo, los deseos de la fase de Edipo son imposibles de satisfacer; el niño, por el contrario, tiene que renunciar a sus tendencias sexuales para con la madre, [...] el complejo de Edipo tiene que fracasar [...] pero eso no impide que el complejo exista y que sea el núcleo alrededor del cual se desarrollan la mayoría de las neurosis. Asimismo, el niño tiene que aprender a desviar y sublimar sus tendencias pregenitales; tiene, por ejemplo, que desarrollar el sentimiento de asco hacia los excrementos, etc. Las personas educadoras del niño deben favorecer esta desviación de los instintos de los objetos inmediatos para que puedan ser dedicados a fines superiores; es decir, su comportamiento para con el niño debe ser algo más que aclararle su sexualidad»58.

Desde este punto de vista, de manera semejante al onanismo, las «desviaciones» sexuales aparecen, en la infancia, como comportamientos normales; pero la educación sexual debe aspirar a que no se prolonguen en la vida adulta, favoreciendo la sublimación de los instintos, regulando las imágenes paterna y materna y reconduciendo el objeto del deseo. Este sería el fin último de la pedagogía sexual de inspiración psicoanalítica, pero también su mayor dificultad. La famosa «aclaración de la sexualidad» resulta insuficiente porque:

«La sexualidad es algo que no se satisface ni con palabras ni con explicaciones sino que requiere un objeto. El confiar que un niño después de explicarle la sexualidad domine estas tendencias es como esperar que el hambre o las tendencias o deseos de cohabitar de un adulto se satisfagan diciéndole que tiene hambre o deseos de cohabitar; a este adulto para hacerle feliz hay que ponerle en condiciones necesarias para que pueda comer o cohabitar. $Y$ esta es la dificultad en el niño»s9.

Por eso, el psicoanálisis, que en la España de los años treinta del siglo XX encarna Ángel Garma, aspira a conseguir que el niño y el joven sublimen el curso de la libido, evitando la represión y el sentimiento de culpa, cuya consecuencia será la neurosis, e impidiendo que dicha energía sexual quede estancada en alguna fase evolutiva anterior (oral, anal-sadista o genital), lo que daría lugar al adulto perverso.

Vemos, pues, cómo, si bien no podemos olvidar que algunos aspectos supuestamente dinámicos del psicoanálisis acaban fusionándose con el organicismo propio de la psiquiatría más tradicional - como, por ejemplo, en lo refe-

58 GARMA, Ángel: El psicoanálisis, la neurosis y la sociedad, op. cit., p. 120.

59 Ibid.

Hispania, LXIV/3, núm. 218 (2004) 987-1002 
rente a la etiología sexual de las neurosis, en la que, como hemos visto, Garma considera la existencia de factores constitucionales predisponentes e inalterables-, lo cierto es que el campo de acción que se propone no es, en esta ocasión, el cuerpo, la herencia, la degeneración ${ }^{60} \ldots$, sino el ambiente familiar y las relaciones interpersonales, desde el convencimiento de que las vivencias infantiles troquelan y condicionan el futuro del adulto en todos los órdenes de su vida.

Novedad importante que nos orienta, una vez más, hacia la coexistencia de paradigmas científicos diversos, no necesariamente enfrentados de manera permanente y que, incluso, pueden llegar a convivir y complementarse con fines normativos.

60 Sobre el degeneracionismo en relación con la infancia, puede verse HUERTAS, Rafael: «Niños degenerados. Medicina mental y regeneracionismo en la España del cambio de siglo», Dynamis (Granada), no 18 (1998), pp. 157-179, y CAMPOS, Ricardo, MARTINEZ-PÉREZ, José, HuERTAS, Rafael: Los ilegales de la naturaleza. Medicina y degeneracionismo en la España de la Restauración (18761923), Madrid, C.S.I.C., 2000. 